CRUCIOL, G. C. D.; KOYANAGUI, M. T.; BATISTA, T. B.; BINOTTI, F. F. S.; COSTA, M. L. N.. Aplicação de ácido giberélico e paclobutrazol na cultura da soja. Revista de Agricultura Neotropical, Cassilândia-MS, v. 1, n. 2, p. 72-79, out./dez. 2014.

\title{
APLICAÇÃO DE ÁCIDO GIBERÉLICO E PACLOBUTRAZOL NA CULTURA DA SOJA
}

\section{GIOVANA CAROLINA DOURADO CRUCIOL ${ }^{1}$, MARLI TIEME KOYANAGUI ${ }^{1}$, THIAGO BARBOSA BATISTA ${ }^{1}$, FLÁVIO FERREIRA DA SILVA BINOTTI ${ }^{1}$, MARIA LUIZA NUNES COSTA ${ }^{2}$}

\footnotetext{
${ }^{1}$ Universidade Estadual de Mato Grosso do Sul, CassilândiaMS, Brasil, giovanacruciol@hotmail.com, m.koyanagui@hotmail.com, batistatb@hotmail.com, binotti@uems.br. ${ }^{2}$ Universidade Federal de Mato Grosso do Sul, Chapadão do Sul/MS, luiza.costa@ymail.com
}

RESUMO: As giberelinas são associadas à promoção do crescimento do caule e sua aplicação na planta pode induzir a um aumento significativo na sua altura. O paclobutrazol é considerado regulador de crescimento utilizado na agricultura com finalidade de controlar o crescimento vegetativo, estimulando a capacidade reprodutiva das plantas. O objetivo foi avaliar o crescimento, mudanças morfológicas e teor de clorofila foliar A, B e total em plantas de soja, mediante a aplicação de ácido giberélico via foliar e de paclobutrazol via solo. $\mathrm{O}$ experimento foi desenvolvido na Universidade Estadual de Mato Grosso do Sul, unidade Universitária de Cassilândia, num delineamento inteiramente casualizado em esquema fatorial de 2 x 2, com aplicação de paclobutrazol via solo (presença e ausência) e giberelina via foliar (presença e ausência), contendo oito repetições. O paclobutrazol reduziu a área foliar, fitomassa seca e diâmetro do caule de plantas de soja. O ácido giberélico propiciou aumento na largura de folíolos, teor de clorofila A e redução da clorofila B. A aplicação conjunta de paclobutrazol e ácido giberélico na cultura da soja propiciaram redução do comprimento de folíolos, largura de folíolos e teor de clorofila A.

PALAVRAS-CHAVE: Glycine max, regulador, hormônio, crescimento, clorofila.

\section{GIBBERELLIC ACID AND PACLOBUTRAZOL APPLICATION IN CULTURE OF SOYBEAN CROP}

\begin{abstract}
Gibberellins are associated with stem growth promotion and its application in plants can induce a significant increase in their height. Paclobutrazol is considered growth regulator, used in agriculture to control vegetative growth, stimulating the plants' reproductive capacity. The objective of this study was to evaluate the growth, morphological changes and leaf chlorophyll content A, B and total in soybean plants by applying gibberellic acid in the leafs and paclobutrazol in the soil. The experiment was conducted at the State University of Mato Grosso do Sul, Cassilândia University Unit in a completely randomized design with factorial arrangement of $2 \times 2$, with application of paclobutrazol in the soil (present and absent) and gibberellin in the leaf (present and absent), with eight replications. Paclobutrazol reduced leaf area, stem dry weight and diameter of the soybean. The gibberellic acid induced an increase in the leaflets' width, chlorophyll A content and the reduction in the chlorophyll B. The joint application of paclobutrazol and gibberellic acid in soybean propitiated length reduction leaflets, width of leaflets and chlorophyll A content.
\end{abstract}

KEY-WORDS: Glycine max., regulatory, hormone, growth, chlorophyll. 


\section{INTRODUÇÃO}

A soja (Glycine max L.) é uma das mais importantes culturas agrícolas na economia mundial. A área cultivada no Brasil na safra 2014/2015 é estimada em 31.698,1 milhões hectares. Com estimativa de produtividade de 2.854 milhões de toneladas por hectare e produção de 91.744,5 milhões de toneladas. (CONAB, 2014).

O crescimento e desenvolvimento vegetal são totalmente influenciados pelos reguladores de crescimento. A aplicação exógena de giberelina provoca um excesso de alongamento do caule em plantas anãs; associada a esse efeito ocorre diminuição na espessura do caule, assim como alongamento dos entrenós (TAIZ; ZEIGER, 2004).

As giberelinas são associadas à promoção do crescimento do caule e a aplicação desse hormônio à planta pode induzir aumento significativo na sua altura. O hormônio, responsável pela regulação de vários processos fisiológicos tais como a germinação de sementes, mobilização das reservas do endosperma, crescimento da parte aérea e florescimento rege diretamente a transcrição do estado juvenil para o maduro e o estabelecimento do fruto (TAIZ; ZEIGER, 2004).

O paclobutrazol é considerado um regulador de crescimento utilizado na agricultura com finalidade de controlar o crescimento vegetativo, estimulando a capacidade reprodutiva das plantas (MILFONT et al., 2008). Esse regulador atua inibindo a síntese de giberelina, hormônio responsável pelo crescimento vegetativo da planta, fazendo com que a mesma cesse seu crescimento e seja estimulada a produção de flores e frutos (VAZ et al., 2012).

O paclobutrazol faz com que proteínas transportadoras de elétrons, que promovem reações no metabolismo vegetal, seja inativada, interrompendo diversas rotas metabólicas, especialmente o metabolismo das giberelinas. $\mathrm{O}$ regulador pode ser aplicado diretamente no tronco de árvores e arbustos, no solo ou por meio de pulverizações diretas nas folhas. $\mathrm{Na}$ folha, o paclobutrazol possui contato direto com os meristemas apicais e entrenós. Em aplicações via solo, o regulador é absorvido pelas raízes e transportado através do xilema para a parte aérea das plantas (LACERDA et al., 2007).

O objetivo deste trabalho foi avaliar o crescimento, as mudanças morfológicas e o teor de clorofila foliar A, B e total em plantas de soja, com aplicação de ácido giberélico foliar e de paclobutrazol via solo.

\section{MATERIAL E MÉTODOS}

O trabalho foi desenvolvido no Laboratório de Análise de Sementes e casa de vegetação da Universidade Estadual de Mato Grosso do Sul, Unidade Universitária de Cassilândia-MS, em setembro de 2014, utilizando a cultivar de soja M6952 IPRO.

$\mathrm{O}$ trabalho foi conduzido num delineamento inteiramente casualizado, em esquema fatorial 2 × 2, constituído da aplicação de paclobutrazol via solo (presença e ausência) e giberelina via foliar (presença e ausência), com oito repetições, sendo cada repetição o conjunto de quatro plantas.

Foi utilizado giberelina na forma de Ácido giberélico $\left(\mathrm{GA}_{3}\right)$ na concentração de 50 ppm. Paclobutrazol na forma de produto comercial CULTAR 250 utilizando $3,2 \mathrm{~mL} \mathrm{~L}^{-1}$.

As sementes de soja foram semeadas em vasos de cinco litros contendo solo de barranco, dispondo 10 sementes por vaso, e após 10 dias da emergência foi realizado o desbaste deixando apenas 4 plantas por vaso. A aplicação do ácido giberélico foi realizada via 
foliar aos 15 dias após a emergência das plantas (DAE), com auxílio de um pulverizador manual aplicando uma calda de $50 \mathrm{~mL}$ por vaso (quatro plantas). A aplicação do paclobutrazol via solo, também aos $15 \mathrm{DAE}$, aplicando calda de $800 \mathrm{~mL}$ por vaso. O fornecimento de água foi realizado diariamente com auxílio de um regador manual.

As plantas foram avaliadas sete dias após as aplicações dos produtos. Foram avaliados: o comprimento da parte aérea $(\mathrm{cm})$, medida do colo até o ápice da planta, comprimento do primeiro nó $(\mathrm{cm})$, medida da altura da base do solo até a inserção do primeiro nó, comprimento do hipocótilo $(\mathrm{cm})$, medida da altura da base do solo até a inserção das folhas cotiledonares, comprimento $(\mathrm{cm})$ e largura de folhas $(\mathrm{cm})$, altura da base da folha até sua extremidade e da distância das duas extremidades das folhas, respectivamente, comprimento e largura de folíolos $(\mathrm{cm})$, altura da base do folíolo até sua extremidade e da distância das duas extremidades dos folíolos, respectivamente. Todos os comprimentos e larguras foram mensurados com régua graduada em centímetros.

Foi realizada a contagem do número de folhas por planta e mensurado o diâmetro do colo (mm), com auxílio de paquímetro.

Foi mensurada a fitomassa fresca da planta $(\mathrm{mg})$ por meio de balança de precisão. Após a secagem das amostras em estufa de circulação forçada de ar, em temperatura média de $65^{\circ} \mathrm{C}$, até que se atingisse massa constante, foi determinada a fitomassa seca (mg) em balança de precisão.

Foram determinadas as clorofilas A, B e total, em laboratório, utilizando 0,5 grama de tecido foliar, macerados, em $10 \mathrm{~mL}$ de acetona; posteriormente o extrato foi centrifugado a $1500 \mathrm{rpm}$ por 10 minutos, e realizadas as leituras com o espectrofotômetro em laboratório; leituras em 645 e $663 \mathrm{~nm}$ de comprimento de onda. Em seguida estas leituras foram utilizadas nas equações sugeridas por Arnon (1949): Clorofila A $(\mathrm{mg} / \mathrm{l})=12,7$ x DO663 - 2,69 x DO645; Clorofila B $(\mathrm{mg} / \mathrm{l})=22,9 \times$ DO645 - 4,69 x DO663; Clorofila total $(\mathrm{a}+\mathrm{b})(\mathrm{mg} / \mathrm{l})=20,2$ x D0645 + 8,02 x D0663.

Foi determinada a área foliar por meio de fotocópias comparando a massa de uma área conhecida de papel com a massa dos recortes do perímetro das folhas. Para isso, foram feitas cópias heliográficas das folhas e do mesmo papel foi retirada figura com forma (quadrado) em que a área foi dimensionada. Por interpolação da massa da figura de área conhecida e a massa da "impressão" recortada da folha, determinou-se a área de uma das faces da folha.

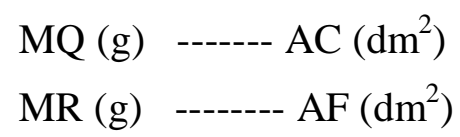

Dado que: massa quadrado $=\mathrm{MQ}$, área conhecida do quadrado $=\mathrm{AC}$, massa dos recortes das folhas por planta ou total de plantas $=\mathrm{MR}$, área foliar da planta ou total de plantas $=\mathrm{AF}$.

Os dados foram avaliados por meio da análise de variância pelo teste $\mathrm{F}$, ao nível de $5 \%$ de probabilidade. Foi utilizado o programa SANEST (ZONTA; MACHADO, 1986).

\section{RESULTADOS E DISCUSSÕES}

As interações entre os fatores estudados só foram significativas para comprimento e largura de folíolos e para clorofila A e B.

A aplicação do paclobutrazol proporcionou menor fitomassa fresca, fitomassa seca e diâmetro do caule de plantas de soja aos 7 dias após a aplicação (Tabela 1). Silva e Faria Junior (2011), observaram que a aplicação do paclobutrazol em mudas de Solanum lycopersicum L., por aspersão, aos 15 dias após a semeadura, nas concentrações de $0 ; 50 ; 100$ e $150 \mathrm{mg} \mathrm{L}^{-1}$, reduziu o número de brotos laterais e a fitomassa seca de brotações das plantas. 
Para número de folhas não houve diferença entre os tratamentos aplicados (Tabela 1). Diferente do resultado de Resende e Souza (2002) que verificaram redução na altura e número de folhas aos 60 e 90 dias após o plantio de bulbos de Allium sativum imersos em paclobutrazol na concentração de 1000 e $1.500 \mathrm{mg}$ do ingrediente ativo por litro.

A aplicação de giberelina não influenciou o comprimento de parte área; primeiro nó e do hipocótilo (Tabela 2), sendo estes resultados divergentes dos verificados por Leite et al. (2003) que ao aplicarem em plantas de soja, com três a quatro folhas trifolioladas completamente abertas, $100 \mathrm{mg} \mathrm{L}^{-1}$ de $\mathrm{GA}_{3}$ constataram aumento da altura de plantas, altura do primeiro nó e diâmetro do colo.

Tabela 1. Fitomassa fresca, fitomassa seca, diâmetro do caule e número de folhas por plantas de Glycine max em função da aplicação de Paclobutrazol via solo e Giberelina via foliar. UEMS Cassilândia (MS), 2014.

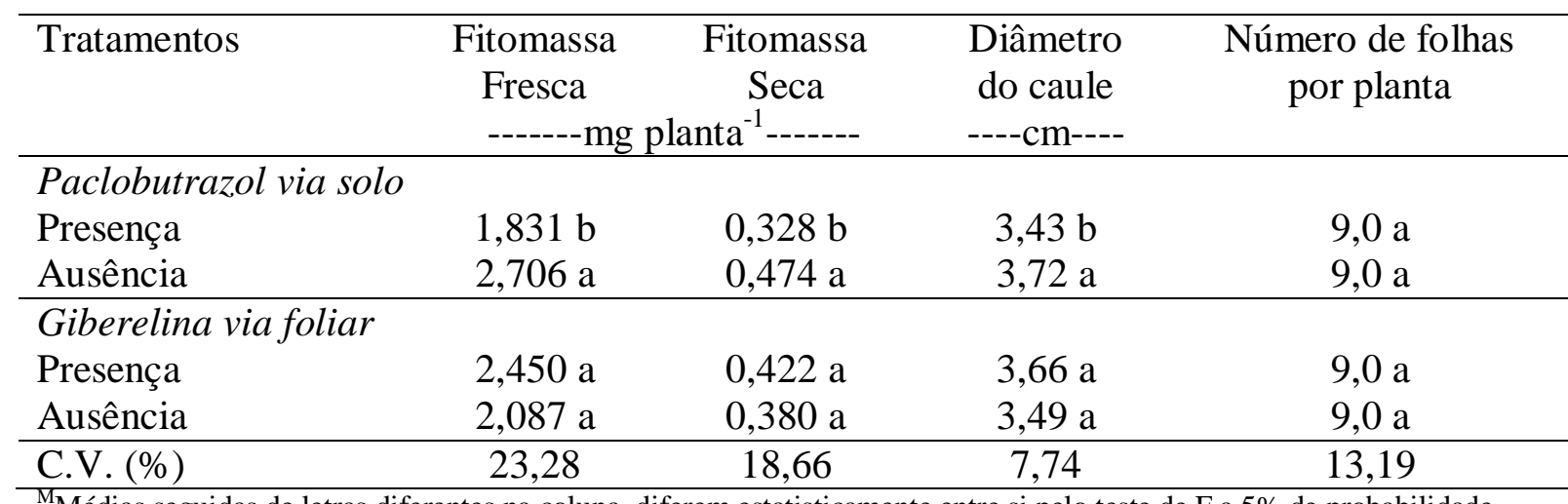

${ }^{\mathrm{M}}$ Médias seguidas de letras diferentes na coluna, diferem estatisticamente entre si pelo teste de $\mathrm{F}$ a $5 \%$ de probabilidade.

Na presença do paclobutrazol via solo em plantas de soja, o comprimento da parte aérea e comprimento do primeiro nó foram maiores quando comparados a sua ausência, porém para comprimento de hipocótilo não houve diferença (Tabela 2). Este resultado foi diferente ao de Blanck et al. (2009) em que a concentração de $1.800 \mathrm{mg} \mathrm{L}^{-1}$ de paclobutrazol, aplicados aos sete e 14 dias após o plantio, resultou em menor altura de mudas de Chrysopogon zizanioides vetiver quando aplicado aos 14 dias após o transplantio.

Tabela 2. Comprimento de parte aérea, comprimento do primeiro nó, comprimento de hipocótilo de plantas de Glycine max em função da aplicação de Paclobutrazol via solo e Giberelina via foliar. UEMS Cassilândia (MS), 2014.

\begin{tabular}{lccc}
\hline Tratamentos & $\begin{array}{c}\text { Comprimento de } \\
\text { parte aérea } \\
---------------------~ \\
\text { cm------------------- }\end{array}$ & $\begin{array}{c}\text { Comprimento do } \\
\text { primeiro nó }\end{array}$ & $\begin{array}{c}\text { Comprimento de } \\
\text { hipocótilo }\end{array}$ \\
\hline $\begin{array}{l}\text { Paclobutrazol via solo } \\
\text { Presença }\end{array}$ & $14,67 \mathrm{a}$ & $9,60 \mathrm{a}$ & $4,36 \mathrm{a}$ \\
Ausência & $12,47 \mathrm{~b}$ & $8,70 \mathrm{~b}$ & $4,13 \mathrm{a}$ \\
\hline Giberelina via foliar & $13,84 \mathrm{a}$ & $9,25 \mathrm{a}$ & $4,26 \mathrm{a}$ \\
Presença & $13,31 \mathrm{a}$ & $9,05 \mathrm{a}$ & $4,23 \mathrm{a}$ \\
Ausência & $12,18 \%$ & 13,15 & 10,77 \\
\hline C.V. (\%) & & &
\end{tabular}


Para Gitti et al. (2012) a aplicação de paclobutrazol em Phaseolus vulgaris L., reduz o comprimento de plantas em $21 \mathrm{~cm}$, comprovando a hipótese de que o paclobutrazol é um inibidor da giberelina e portanto diminui suas concentrações endógenas.

O comprimento e largura de folíolos foram menores na presença de paclobutrazol. $\mathrm{Na}$ ausência da aplicação de paclobutrazol a presença de giberelina propiciou maior largura de folíolos (Tabela 3).

Tabela 3. Desdobramento da análise de variância de comprimento e largura de folíolos de plantas de Glycine max em função da aplicação de Paclobutrazol via solo e Giberelina via foliar. UEMS Cassilândia (MS), 2014.

\begin{tabular}{|c|c|c|c|c|}
\hline \multirow{2}{*}{ Tratamentos } & \multicolumn{4}{|c|}{ Giberelina via foliar } \\
\hline & Presença & Ausência & Presença & Ausência \\
\hline Paclobutrazol via & \multicolumn{2}{|c|}{ Comprimento de folíolos } & \multicolumn{2}{|c|}{ Largura de folíolos } \\
\hline Presença & ${ }^{M_{6,26} \mathrm{bA}}$ & 6,66 aA & $7,78 \mathrm{bA}$ & $8,09 \mathrm{aA}$ \\
\hline Ausência & $7,54 \mathrm{aA}$ & $6,88 \mathrm{aA}$ & $9,19 \mathrm{aA}$ & $8,21 \mathrm{aB}$ \\
\hline C.V.(\%) & \multicolumn{2}{|c|}{9,79} & \multicolumn{2}{|c|}{8,48} \\
\hline
\end{tabular}

Em relação ao teor de clorofila A (Tabela 4) nas folhas, na presença de giberelina, a aplicação de paclobutrazol proporcionou menor valor de clorofila A, já na ausência de paclobutrazol a aplicação de giberelina propicia maior valor de clorofila A. Em relação ao teor de clorofila B nas folhas, os resultados foram inversos aos obtidos na clorofila B.

Tabela 4. Desdobramento da análise de variância de clorofila A e B de plantas de Glycine max em função da aplicação de Paclobutrazol via solo e Giberelina via foliar. UEMS Cassilândia (MS), 2014.

\begin{tabular}{|c|c|c|c|c|}
\hline \multirow{2}{*}{ Tratamentos } & \multicolumn{4}{|c|}{ Giberelina via foliar } \\
\hline & Presença & Ausência & Presença & Ausência \\
\hline Paclobutrazol via & \multicolumn{2}{|c|}{ Clorofila A } & \multicolumn{2}{|c|}{ Clorofila B } \\
\hline Presença & ${ }^{\mathrm{M}_{5,19} \mathrm{bA}}$ & $6,30 \mathrm{aA}$ & $2,33 \mathrm{aA}$ & $2,93 \mathrm{aA}$ \\
\hline Ausência & $9,89 \mathrm{aA}$ & $6,14 \mathrm{aB}$ & $1,38 \mathrm{bB}$ & $3,23 \mathrm{aA}$ \\
\hline C.V.(\%) & \multicolumn{2}{|c|}{17,92} & \multicolumn{2}{|c|}{29,87} \\
\hline
\end{tabular}

${ }^{\mathrm{M}}$ Médias seguidas de letras maiúscula diferentes nas linhas e minúscula nas colunas, diferem estatisticamente entre si pelo teste $\mathrm{F}$ a $5 \%$ de probabilidade.

A ausência do paclobutrazol apresentou um menor valor de clorofila total (Tabela 5). Da mesma forma Gitti et al. (2012) aplicaram paclobutrazol em Phaseolus vulgaris L., e notaram que o índice de clorofila foliar foi menor na ausência do regulador. Campos et al. (2010) notaram que a aplicação de giberelina em plantas de soja também não alterou o teor de clorofila das folhas.

Para comprimento e largura de folhas na presença e ausência de paclobutrazol e giberelina não se observou influências nessas características (Tabela 5). Vichiato et al. (2007) fizeram 4 pulverizações de giberelina, com intervalos de 15 dias, em plantas de orquídeas e aos 90 dias após a primeira aplicação observaram um aumento de $44 \%$ no comprimento de 
folhas, porém as larguras das folhas foram menores comparadas a testemunha, relatando que a giberélica atua na expansão celular longitudinal.

A presença de placobutrazol reduziu a área foliar de soja aos sete dias após a aplicação, da mesma forma que ocorreu com a fitomassa seca e fresca de plantas. De acordo com Siqueira et al., (2008) o paclobutrazol na ausência de giberelina reduziu a área foliar de plantas de limoeiro.

Tabela 5. Clorofila total, largura de folhas, comprimento de folhas, e área foliar por planta de Glycine max em função da aplicação de Paclobutrazol via solo e Giberelina via foliar. UEMS Cassilândia (MS), 2014.

\begin{tabular}{|c|c|c|c|c|}
\hline Tratamentos & $\begin{array}{l}\text { Clorofila total } \\
\text {--- } \mathrm{mg} \mathrm{L}^{-1} \text { - }\end{array}$ & $\begin{array}{l}\text { Largura de } \\
\text { folhas } \\
-- \text { cm--- }\end{array}$ & $\begin{array}{l}\text { Comprimento } \\
\text { de folhas } \\
\text {----cm----- }\end{array}$ & $\begin{array}{l}\text { Área foliar } \\
--\mathrm{cm}^{2}--\end{array}$ \\
\hline $\begin{array}{l}\text { Paclobutrazol via solo } \\
\text { Presença } \\
\text { Ausência }\end{array}$ & $\begin{array}{c}{ }^{\mathrm{M}} 10,88 \mathrm{a} \\
8,80 \mathrm{~b}\end{array}$ & $\begin{array}{l}3,98 \mathrm{a} \\
3,75 \mathrm{a}\end{array}$ & $\begin{array}{l}5,31 \mathrm{a} \\
4,95 \mathrm{a}\end{array}$ & $\begin{array}{l}65,78 \mathrm{~b} \\
77,79 \mathrm{a}\end{array}$ \\
\hline $\begin{array}{l}\text { Giberelina via foliar } \\
\text { Presença } \\
\text { Ausência }\end{array}$ & $\begin{array}{l}9,86 \mathrm{a} \\
9,83 \mathrm{a}\end{array}$ & $\begin{array}{l}3,89 \mathrm{a} \\
3,84 \mathrm{a}\end{array}$ & $\begin{array}{l}5,17 \mathrm{a} \\
5,09 \mathrm{a}\end{array}$ & $\begin{array}{l}74,17 \mathrm{a} \\
69,40 \mathrm{a}\end{array}$ \\
\hline C.V. (\%) & 24,75 & 12,01 & 10,56 & 13,94 \\
\hline
\end{tabular}

${ }^{\mathrm{M}}$ Médias seguidas de letras diferentes na coluna, diferem estatisticamente entre si pelo teste de $\mathrm{F}$ a $5 \%$ de probabilidade.

Na Figura 1 se verificou que os tratamentos utilizados influenciaram o crescimento e a morfologia de plantas de soja, evidenciando que na presença de placobutrazol $\left(\mathrm{T}_{1}\right.$ e $\left.\mathrm{T}_{3}\right)$ as plantas apresentaram menor comprimento da parte aérea.

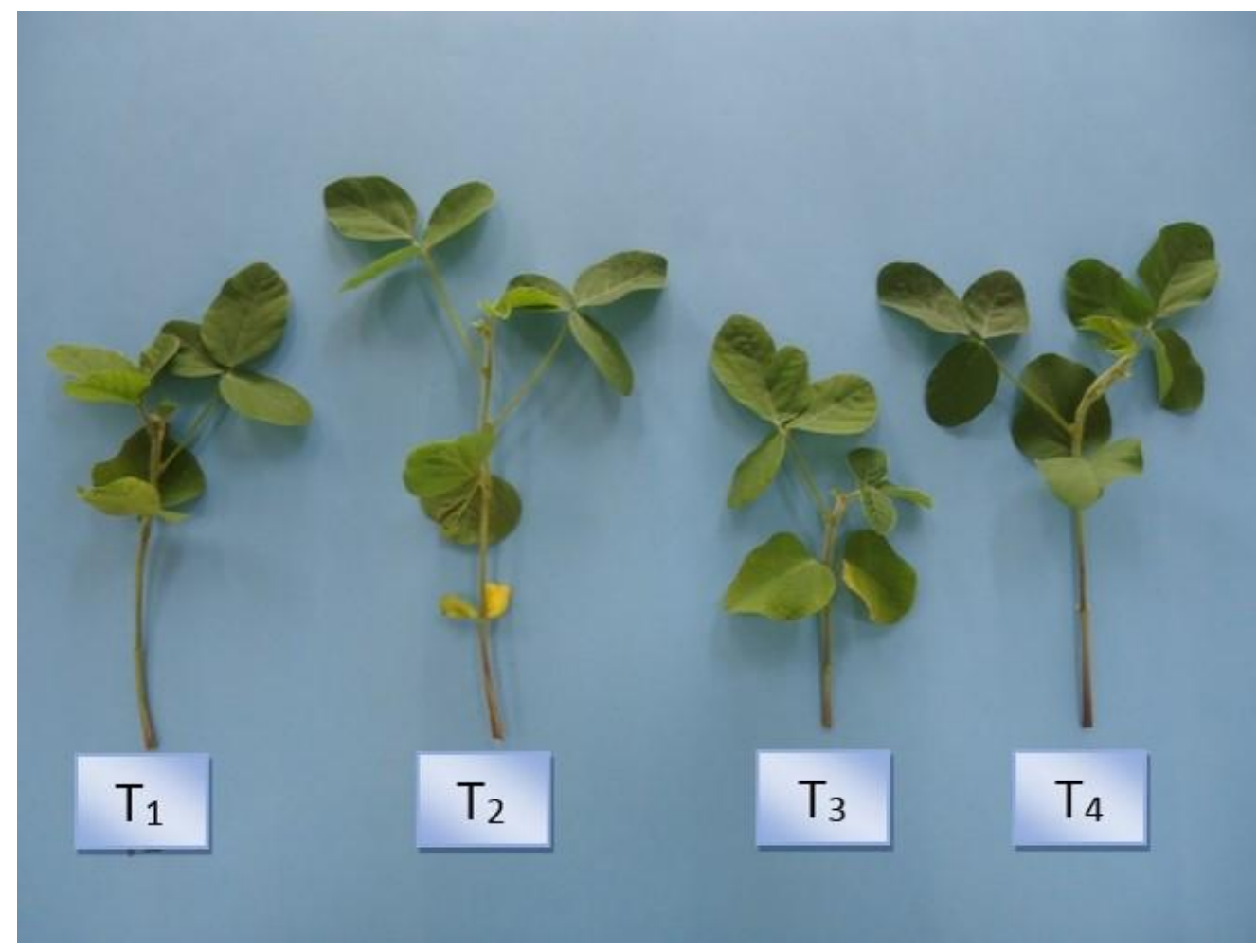

Figura 1. Exemplares de cada tratamento, T1 (ácido giberélico, via foliar + paclobutrazol, via solo); T2 (ácido giberélico, via foliar); T3 (paclobutrazol, via solo); T4 (ausência de produtos). 
O tratamento com giberelina $\left(\mathrm{T}_{2}\right)$ apresentou plantas com maior crescimento (Figura 1). Cardoso (2013) enfatiza que sob tratamento com determinadas giberelinas a maioria das dicotiledôneas crescem mais rápido, sendo o crescimento do caule o mais proeminente.

\section{CONCLUSÕES}

1. O paclobutrazol reduziu a área foliar, fitomassa seca e diâmetro do caule de plantas de soja.

2. O ácido giberélico propiciou aumento na largura de folíolos, teor de clorofila a e redução da clorofila $B$.

3. A aplicação conjunta de paclobutrazol e ácido giberélico na cultura da soja propiciaram redução do comprimento de folíolos, largura de folíolos e teor de clorofila A.

\section{REFERENCIAS BIBLIOGRÁFICAS}

ARNON, D. I. Copper enzymes in isolated chloroplasts: polyphenol oxydase in Beta vulgaris. Plant Physiology. Maryland, v. 24, n.1, p.1-15, 1949.

CAMPOS, M. F.; ONO, E. O.; RODRIGUES, J. D. Arquitetura de plantas de soja e a aplicação de reguladores vegetais. Pesquisa Aplicada \& Agrotecnologia, Guarapuava-PR, v. 3, n 1, p. 153-159. 2010.

CARDOSO, V. J. M. Giberelinas. In: KERBAUY, G. B. Fisiologia vegetal. Rio de Janeiro: GEN - Guanabara Kooga, 2013. p. 235-254.

CONAB. COMPANHIA NACIONAL DE ABASTECIMENTO. Acompanhamento da safra brasileira de grãos. Safra 2014/2015: segundo levantamento. v. 2, n. 2. Brasília-DF: Conab, novembro2014. Disponível em: http://www.conab.gov.br. Acesso em: 01 de dezembro de 2014.

BLANK, A. F.; PAULA, J. W. A; ARRIGONI-BLANK, M. F.; MOREIRA, M. A. Utilização de paclobutrazol em vetiver na produção de mudas e seu efeito em plantas no campo. Horticultura Brasileira, Brasília-DF, v. 27, n. 4 p. 425-430. 2009.

GITTI, D. C.; ARF, O.; BUZETTI, S.; FERREIRA, M. M. R.; KAPPES, C.; KANEKO, F. H.; RODRIGUES, R. A. F. Aplicação de paclobutrazol e doses de nitrogênio em feijão de inverno cultivado em sistema plantio direto. Scientia Agraria Paranaensis, Cascavel-PR, v. 11, n. 3, p.35-46, 2012.

LACERDA, C. F.; ENÉAS FILHO, J.; PINHEIRO, C. B. Fisiologia vegetal. Fortaleza-CE: Universidade Federal do Ceará, 2007. 332 p.

LEITE, V. M.; ROSOLEM, C. A.; RODRIGUES, J. D. Gibberellin and cytokinin effects on soybean growth. Scientia Agricola, Piracicaba-SP, v. 60, n. 3, p. 537-541, 2003.

MILFONT. M. L.; ANTONINO, A. C. D.; MARTINS J. M. F.; MACIEL NETTO, A.; GOUVEIA, E. R.; CORREA, M. M. Transporte do paclobutrazol em colunas de solos. Revista Brasileira Ciência do Solo, Recife-PE, v. 32, n. 5, p. 2165-2175, 2008.

RESENDE, G. M.; SOUZA, R. J.; Efeito de doses de paclobutrazol na cultura do alho. Pesquisa Agropecuária Brasileira, Brasília-DF, v. 37, n. 5, p. 637-641, 2002. 
SILVA, K. S.; FARIA JUNIOR, M. J. A. Uso de paclobutrazol como estratégia para redução do porte e da brotação lateral de plantas de tomateiro. Ciência e Agrotecnologia, Lavras-MG, v. 35, n. 3, p. 539-546, 2011.

SIQUEIRA, D. L.; SALOMÃO, L. C. C.; CECON, P. R.; BARROS, Z. J. ; FERNANDES, A. R. Distribuição da massa de matéria seca em limoeiro 'Volkameriano' submetido a diferentes doses de paclobutrazol e ácido giberélico. Revista Ceres, Viçosa-MG, v. 55, n. 6, p. 512-517, 2008.

TAIZ, L.; ZEIGER, E. Fisiologia vegetal. 3. ed . Porto Alegre-RS: Artmed, 2004. 719 p.

VAZ, F. L.; MACIEL NETTO, A.; ANTONINO, A. C. D.; GOUVEIA, E. R.; MARTINS, J. M. F. Biodegradação de paclobutrazol por pseudomonas spp. em sistemas de solo saturados. Química Nova, São Paulo-SP, v. 35, n. 6, p.1090-1096, 2012.

VICHIATO, M. R. M.; VICHIATO, M.; CASTRO, D. M.; DUTRA, L. F.; PASQUAL, M. Alongamento de plantas de Dendrobium nobile lindl. com pulverização de ácido giberélico. Ciência e Agrotecnologia, Lavras-MG, v. 31, n. 1, p. 16-20, 2007.

ZONTA, E. P.; MACHADO, A. A. Sistema de Análise Estatística para microcomputadores - SANEST. Pelotas: UFPEL, Instituto de Física e Matemática, 1986. $150 \mathrm{p}$. 